\title{
5 La cadena productiva de la literatura mundial. Actores y procesos
}

Aunque no siempre se haga explícito, no es poco lo que este capítulo le debe al excelente libro de William Marling, Gatekeepers: The Emergence of World Literature and the 1960s (2016). Cuando apareció este estudio, mi libro estaba en proceso de escritura y varios apartados ya habían sido adelantados en diferentes encuentros académicos. La posterior lectura de Gatekeepers, sin duda, me permitió conceptualizar mejor algunas hipótesis de mi propia investigación. De todos modos, como ya he sugerido en páginas anteriores, creo que una sociología de la literatura que pierde de vista el texto resulta tan insuficiente para dar cuenta de la producción de literatura como los abordajes puramente formales que olvidan evaluar las condiciones materiales específicas bajo las cuales tiene lugar el complejo proceso productivo. Por otra parte, mientras que Marling deposita su atención en los años 60 y, entre otros casos no latinoamericanos, en Gabriel García Márquez como fenómeno ejemplar de producción de literatura mundial, mi foco está puesto en los productos y procesos que han tenido lugar desde la Caída del Muro y el consecuente reordenamiento de la geopolítica global desde los años 90 en adelante.

Este capítulo está orientado a examinar mecanismos y actores específicos que intervienen y gobiernan el nivel de la literatura mundial con especial atención a la literatura de cuño latinoamericano o puesta en circulación como tal. Formulado en otros términos, busco responder a la pregunta por cómo se elabora en la actualidad la literatura latinoamericana mundial. Dos premisas resultan fundamentales para comprender mejor las próximas páginas.

En primer lugar, como ya ha sido adelantado, el sistema de producción de literatura mundial debe ser concebido en contraste con el de las literaturas locales, que van a ser tema del capítulo IV. Esto no necesariamente implica oposición o demarcación maniquea. La comunicación y los flujos entre un nivel y el otro son sin duda posibles y existen evidencias que así lo constatan, pero esto no alcanza para desmentir la afirmación de que ambos niveles están gobernados por lógicas disímiles, que las condiciones materiales de cada dominio difieren entre sí particularmente cuando se atiende a los sistemas de producción periféricos- $y$, por supuesto, que los correspondientes horizontes de expectativas no son equiparables. Este esquema es el que permite explicar el frecuente desfasaje valorativo entre un sistema y otro. Una mirada poco atenta tendería a pensar que el éxito (de ventas, de crítica, de valoración en el campo más especializado) a nivel local conduce al éxito nacional y de ahí al internacional o mundial, como una serie de procesos escalonados. Sin embargo, abundan evidencias de que no existen

Ә Open Access. (c) 2019 Jorge J. Locane, published by De Gruyter. (c))BY-NC-ND This work is licensed under the Creative Commons Attribution-NonCommercial-NoDerivatives 4.0 License. 
implicaciones directas y/o determinantes que conducen del dominio más específico al más general. Mario Levrero, por ejemplo, vale por un escritor con amplísimo reconocimiento a nivel local y nacional, no así -por lo pronto porque hasta el momento apenas existen traducciones de su extensa producción- en el nivel mundial. Elsa Osorio, por el contrario, cuenta con el mismo reconocimiento a nivel internacional ${ }^{1}$ sin que esto posea un aval a nivel nacional. ${ }^{2}$ En esta no correspondencia funda su estudio Marling: "One might reply that writers have to achieve success in a home culture or language before this possibility even arises and that commerce then takes care of the rest. But as I will show in the following chapters, local failure is not limiting and local success guarantees little. Success in World Literature is about gatekeeping" (1). Sobre los actores que intervienen en la elaboración de literatura latinoamericana mundial, los gatekeepers concretos, voy a avanzar en las próximos apartados, lo que me interesa destacar en este momento es que las estrategias de posicionamiento en el campo internacional son específicas y que no necesariamente toman como punto de partida o suponen conquistas de terreno en niveles más domésticos.

El segundo aspecto que conviene tener desde ya presente es que el concepto producción de literatura en estas páginas se debe entender como un fenómeno en intersección entre el dominio cultural y el comercial, pero ante todo, y fundamentalmente, de carácter social y colectivo. Si la imagen romántica del escritor como sujeto creador aislado constituye una construcción más o menos superada en todos los posibles órdenes de análisis, en lo que refiere a la literatura mundial esta imagen resulta todavía más cuestionable. El escritor de la literatura mundial puede ser en casos responsable de la orientación general o de algunos o varios trazos estilísticos del texto, pero sin la asistencia de numerosos actores especializados en tráficos culturales jamás estaría en condiciones de producir literatura, entendida como un fenómeno de encadenamiento de acciones y rituales sociales en torno al objeto libro, y mucho menos mundial. También Marling advierte que en particular la literatura mundial, donde la cadena productiva se complejiza y los actores aumentan en cantidad, debe ser entendida como un fenómeno colectivo:

1 Según una nota de prensa aparecida en 2014 en télam, su novela A veinte años, Luz (1998) "lleva más de medio millón de ejemplares vendidos en todo el mundo, ha sido traducida a dieciséis idiomas y editada en veintitrés países”.

2 Sobre este aspecto, puede consultarse la tesis doctoral de Silja Helber quien examina las razones para la diferencia de éxitos de dos escritores mexicanos: Valeria Luiselli, con gran proyección a nivel internacional, y Julián Herbert, quien antes destaca por su repercusión a nivel local y nacional. Otro estudio dedicado a Valeria Luiselli y la propagación internacional de su producción se halla en Sánchez Prado Strategic. 
Friends, family, editors, agents, lawyers, bookstore owners, other artists, patrons, partners, and publishers play an important role in the creative process. Even rivals may help by pushing writers toward new aesthetic paths or by re-dimensioning the creative field or its rules, the doxa as Pierre Bourdieu termed them. We see the value of such aid when we look at writers around us, who are helped by numerous people, not to mention tenure and grants, prizes, and sinecures.

But we have yet to extend this understanding to World Literature, where publication and success are much more difficult. [...] In order to reach foreign readers, it is essential for writers of World Literature to be discovered, translated, promoted, and reviewed. (1) ${ }^{3}$

Y si bien se podría argumentar que muchos de estos actores intervienen en dominios de la institución literaria que no van a afectar directamente la configuración del texto, me interesa destacar la hipótesis, ya anticipada con Thompson, que sostiene que, aunque sea de modo indirecto, muchas de estas intervenciones terminan por producir texto. Un texto -téngase presente- que está destinado a sufrir un traslado de un contexto o sistema de referencias a un horizonte de expectativas "extranjero" y que, por lo tanto, debe ser de algún u otro modo adaptado a condiciones de recepción que el sujeto que asume la función autor muchas veces desconoce. De manera que es posible sostener, acá también en línea con Marling, que, además de que los mediadores son imprescindibles para una efectiva puesta en circulación internacional de un texto, "it's clear that many gatekeepers have a hand in the writing process" (144). Este enfoque, como proponen Sarah Brouillette y Christopher Doody sobre la base de argumentos de Simone Murray, conduce a pensar la producción de literatura del mismo modo que la producción de cine, donde el mito del sujeto creador aislado no cuenta con ningún sustento $\mathrm{y}$, por lo tanto, el producto terminado es atribuible a un equipo de producción o sujeto colectivo. Sostienen Brouillette y Doody que "Book historians have shown that the production of literature is a social process in which many agents, influenced by political, social, and economic concerns, work to produce a given book. To treat the literature industry as separate is to ignore basic features of its contemporary production" (105). Como se sugiere con el epígrafe que encabeza este capítulo, el término “obra”, según lo ha construido la tradición de pensamiento de raigambre romántica, ejerce un borramiento encubridor, precisamente, de los mecanismos comprometidos en la elaboración

3 Del mismo modo, Venkat Mani anota: "I seek to draw attention to the very large body of actors - beyond the author and the translator of a literary work - who determine a reader's access to literary works. If a work of literature originates in a space beyond the immediate geolinguistic location of the reader, the number of actors increases exponentially. If the author and the reader were to be tentatively imagined in a producer-consumer relationship, there is also an entire set of mediators, crossing many institutions and media, who enable the distribution and circulation of a literary artifact for a worldwide readership" (38-39). 
de literatura. Contribuye, así, a una mitificación fetichista de su carácter como "excepcional".

En lo que respecta de modo más específico a la literatura mundial, la cadena productiva, comprendida por la acción concatenada de los sujetos individuales e instituciones que van a mediar en la elaboración del producto final, se torna más compleja y decisiva que en la escala local. No solo aparecen más actores, como agentes literarios y traductores, sino que varios de estos actores deben ser portadores de una doble competencia cultural: van a ser expertos al mismo tiempo en ciertos aspectos, como el lingüístico, de la cultura de origen y de la de recepción. Van a poder evaluar a priori, o dado el caso actuar en consecuencia, el impacto o la recepción que un texto extranjero puede tener en el mercado/cultura de acogida. Estos actores, al ser reconocidos por la estructura productiva como expertos en objetos y tráficos culturales específicos, concentran un cierto poder de decisión en lo que atañe a la selección y jerarquización de las literaturas que, efectivamente, van a entrar en circulación internacional. Esta competencia, así como la de abogados expertos en derechos de autor o periodistas culturales reconocidos como conocedores de la literatura mundial, es lo que permite concebir esta estructura productiva como "profesional”. Cada uno de los mediadores desempeña una función específica altamente especializada, de modo que no puede ser reemplazada o elidida sin perjuicio de la dinámica productiva general. Esto, a su vez, implica que cada una de estas intervenciones tiene que ser compensada económicamente, con lo cual la cadena de agregado de valor va a poseer un costo necesariamente creciente en comparación con la de las literaturas locales. Un costo que, además de que hace a la profesionalidad de la estructura productiva, tiene que ser cubierto con dinero líquido, normalmente anticipado por la editorial, del que se espera, y no puede ser de otra manera para que la industria siga en funcionamiento, un retorno rápido y seguro. Esta última consideración debe ser acentuada, pues no se trata de entender los procesos de elaboración de literatura mundial desde una perspectiva fundada en una encubierta teoría del complot. Frente a un enfoque semejante, el argumento desarrollado en estas páginas se apoya en la observación de que la producción de literatura mundial, precisamente porque requiere una serie de competencias y recursos prescindibles en la escala local, porque se trata de un artefacto altamente sofisticado y de factura colectiva, posee un significativo costo económico que debe ser solventado para que el sistema se mantenga en sano funcionamiento. Esto es lo que permite explicar que el polo heterónomo, en el campo internacional, gane en importancia al punto de determinar la lógica completa de la estructura, o, dicho de otro modo, lo que aquí constituye un factor decisivo es que un pacto con los sectores proveedores de capital resulta, en este nivel, condición insoslayable. Junto a esto conviene agregar, también con Bourdieu, que el trabajo no consiste en identificar comportamientos "corruptores" de los principios de la literatura autónoma, sino de 
visibilizar cómo las posiciones en el campo condicionan los comportamientos y establecen márgenes de acción. Dicho esto, en lo que sigue voy a intentar presentar un examen, en mayor detalle y con referencias concretas, de este modo de producción.

Si bien cada estructura editorial posee sus matices, también es posible identificar ciertas regularidades en lo que hace a actores y funciones. Cualquier editorial influyente en el circuito de tráficos internacionales recurre en algún momento del proceso productivo a las competencias específicas de scouts, agentes, lectores, directores comerciales, gerentes de ventas y marketing, editores (generales y/o de colección), diseñadores, ilustradores, encargados de derechos internacionales, correctores, distribuidores y periodistas culturales. Los momentos pueden ser clasificados en tres: una etapa de preproducción consistente en la adquisición de contenidos o materias primas y planificación general, una etapa de producción o manufacturación del objeto libro y una posproducción definida por las acciones necesarias para una efectiva puesta en circulación, venta y visibilización del libro en tanto objeto ya acabado.

Bajo las actuales condiciones, donde unos pocos grandes conglomerados concentran el poder de movilizar los recursos necesarios para producir literatura mundial -voy a profundizar en algunos aspectos de la concentración en el próximo apartado-, difícilmente pueden elidirse instancias de mediación que antiguamente no resultaban necesarias. El vínculo directo entre autor y editor que caracterizó el "momento clásico", ya comentado con Escalante Gonzalbo, se diluye para dar lugar a una relación mediada por actores emergentes representantes de una visión más mercantil de la literatura. Como anota Gustavo Sorá,

\footnotetext{
[La] modalidad directa de los intercambios declina hacia fines de los años 80. A partir de entonces los libros de un mercado son definidos por la acción cada vez más acentuada de especialistas como los editores, los agentes literarios, los scouts y otras figuras de mercadocultural que seleccionan lo transportable, lo traducible, lo editable, lo legible en diferentes espacios editoriales nacionales. Si un autor argentino pasa a ser bien editado en Brasil, como Tomás Eloy Martínez (Companhia das Letras) o Federico Andahazi (Relume \& Dumará) en tiempos recientes, su elección con frecuencia creciente se dirime, más allá de sus cualidades “intelectuales”, en Frankfurt, a través de la acción de especialistas en la mediación de intercambios internacionales, como la agente literaria Carmen Balcells de Barcelona, la alemana Ray-Güde Mertin o la francesa Anne-Marie Métailié. (126-127)
}

Así, scouts y agentes pasan a ser los principales recolectores y proveedores de materias primas. Su función, decisiva en el nivel de los tráficos internacionales, consiste en seleccionar, en casos acondicionar y a continuación ofrecer a las editoriales textos con un cierto potencial de ventas garantizado. Ambos cuentan con un doble conocimiento en la medida que monopolizan información relativa a novedades y tendencias de los mercados locales en los que tienen jurisdicción y, al 
mismo tiempo, están atentos a las necesidades y demandas del dominio internacional. Se distinguen, fundamentalmente, en que mientras que los primeros ofrecen sus servicios a las editoriales, muchas veces en relación de dependencia directa y exclusiva, y actúan como corresponsales a la caza de primicias aún inéditas, los segundos trabajan para los escritores -se posicionan como representantes de sus intereses económicos y jurídicos-, son freelancers, e intentan conseguir las mejores condiciones de contratación para ellos a cambio de un porcentaje que suele rondar el 10\% de los beneficios percibidos por el escritor. Como ya he comentado, esta fase de selección de material suele priorizar las condiciones de mercado y recepción en el espacio de acogida, de modo que un éxito relativo en el terreno local o nacional no necesariamente se traduce en un tipo de atractivo favorable a la puesta en circulación internacional. Por el contrario, puede haber textos que no tengan o prometan impacto a nivel local o nacional, pero que sí van a resultar favorecidos por scouts o agentes por la expectativa de ventas que prometen en el o los mercados de colocación. Otra aspecto a tener en cuenta es que, si en el "momento clásico" un texto podía ser evaluado por su relativo valor literario o estético y convertirse en una apuesta a largo plazo aunque en el presente no pudiera garantizar ventas; desde la consolidación del "momento monopólico", a los textos se les suele pedir cierta garantía de autosustentabilidad. Esto significa que en la actualidad el material ofrecido por agentes y scouts debe "valer por sí mismo", lo que equivale a decir que debe poder cubrir por sí mismo los futuros costos de manufacturación y puesta en circulación sin dejar margen para grandes riesgos. La figura del scout es más reciente que la del agente literario y esto puede interpretarse como un índice de la creciente importancia de la importación de materias primas o literatura ya elaborada hacia los mercados más consolidados del mundo. Un agente literario bien puede actuar como representante en el terreno nacional o local, pero para un scout el desdoblamiento de órdenes culturales y económicos es condición para su existencia. Tanto en un caso como en el otro, la declinación dominante suele ser femenina. Algunas scouts con cierta trayectoria e importancia en lo que respecta al tema de este libro son Koukla Maclehose (vinculada a Anagrama), Michi Strausfeld (a Fischer del grupo alemán Holtzbrinck) y Carmen Pinilla (proveniente de la agencia Balcells, ahora vinculada a Suhrkamp también de Alemania). Entre los agentes, al margen de los clásicos y decisivos Carmen Balcells -desde su fallecimiento en 2015 como agencia- y Andrew Wylie -ahora a cargo de la gestión de los derechos de Roberto Bolaño- se pueden nombrar a Antonia Kerrigan, a Nicole Witt -de la agencia Mertin- a Andrea Montejo -fundadora de Indent- y a las agencias Casanovas \& Lynch, Schavelzon y Graham y VicLit. Para el caso de estas últimas, incluida Anagrama que suele operar como una agencia de facto, su sede física suele ser, por tradición y regla general, Barcelona, con algunas excepciones más recientes como Indent que se localiza en Nueva York, la Literarische Agentur Michael Gaeb 
con sede en Berlín, CBQ ubicada en Madrid, y ya fuera del circuito hegemónico Irene Barki, en Buenos Aires y Verónica Flores, en México D.F. ${ }^{4}$

Con la intervención de estos actores se inicia el proceso de preproducción. En casos, es posible que agentes y scouts soliciten a los escritores adaptaciones, ya sea de registro o de contenido, o escrituras por encargo con el fin de facilitar la colocación de los textos en circuitos internacionales. Y, si bien el foro por antonomasia donde ejercen su función es sin duda la Feria del Libro de Frankfurt, seguida de las de Londres y Guadalajara -al menos para la literatura que aquí interesa-, su terreno de acción no se agota allí sino que el vínculo con diferentes protagonistas de la industria editorial es regular, cotidiano y más o menos informal. Algunas editoriales, como Anagrama, procuran prescindir de la mediación de los agentes con el fin de entablar un diálogo directo con los escritores y evitar, de este modo, tanto la comisión que les corresponde así como otras negociaciones y constricciones que elevan los costos de producción y reducen el margen de ganancia. En estos casos, la editorial, por mediación de su departamento de derechos internacionales, suele asumir la representación y la gestión de derechos en futuras transacciones. Este modelo, si bien aún existente y posible, debe ser considerado residual y en extinción. Como he señalado con Sorá, el diálogo y negociación directa entre escritores y editores desde los años 90 en adelante, al menos en el nivel de los flujos internacionales, se han reducido marcadamente. Las editoriales, de este modo, tercerizan la preselección de material y establecen un filtro, que de otro modo implicaría costos directos en tiempo y dinero y que, al estar en manos de expertos sobre los que se deposita una confianza profesional, reduce riesgos de inversión de manera significativa. La primera condición en la literatura mundial es, por lo tanto, la intervención de agentes y scouts. Lo que, invirtiendo los términos, implica que sin mediación de estos gatekeepers difícilmente un texto pueda ingresar hoy en día en el corpus de la literatura mundial.

El proceso de preproducción suele continuar con la acción de los lectores. Por lo general se desempeñan como expertos independientes, es decir, que leen y redactan informes de lectura para varias editoriales y reciben un pago por cada informe redactado. La competencia cultural y lingüística de estos actores es de importancia comparable a la de agentes y scouts. No se trata de un procedimiento exclusivo, pero en los casos en que un texto originado en un sistema cultural y lingüístico específico se somete a evaluación para ser insertado en otro contexto, un lector debe dominar por lo menos la lengua de origen y la de destino, debe

4 Para más precisiones en lo que respecta a agencias influyentes en los tráficos internacionales de literatura latinoamericana, véase Locane "La mediación...". 
poder leer el texto original y también poder redactar el informe en la lengua a la que se proyecta traducir el texto. Aparejada con esta competencia lingüística, los lectores deben ser sensibles a los respectivos atributos culturales. Su mirada, no obstante, está más atenta a la línea editorial y a las condiciones del mercado de inserción. Un informe suele estar compuesto por un resumen, por una evaluación del texto en sí y por una de la viabilidad de su inserción en el catálogo de acogida y en el sistema de consumo cultural de destino. Esto significa que un texto puede perfectamente ser evaluado como valioso en términos formales pero inviable para el catálogo o para el mercado en el que se lo pretende colocar. En los casos en los que el texto está redactado en la misma lengua en que se lo proyecta publicar, la competencia del lector debe poder detectar en qué medida ese texto es susceptible de tener una buena recepción en el sistema cultural de acogida. Pero esta evaluación puede contener, implícitamente, una evaluación más amplia, relativa a una circulación de mayor trascendencia, incluso, ya en traducción, en otros circuitos lingüísticos. Valga esta aclaración para el caso de textos que son evaluados para una importación desde América Latina hacia España, pero con miras hacia un horizonte más amplio. Puesto que este itinerario, el que supone una instancia de mediación y visibilización previa en España, es de capital importancia para la suerte de la literatura latinoamericana en el mundo, voy a examinar algunos casos de este tipo, mediante documentos de archivo, en próximos apartados. Sobre los lectores, resta subrayar acá que su función, a pesar de su significativa invisibilidad, es determinante para la literatura mundial: no solo concentran un importante poder de filtrado y selección sino que también reducen de manera decisiva el margen de riesgo al que se expondría una editorial con decisiones no acertadas.

Una vez que un texto es evaluado positivamente y el editor responsable de una colección o sello aprueba su publicación, comienza la fase de negociaciones por el anticipo en concepto de derechos de publicación. Además de la variable dinero, el contrato va a contener especificaciones referidas al tiempo y al espacio que van a regir para el acuerdo. La exitosa restricción de estas dos últimas variables es lo que ha consagrado a Carmen Balcells como una singular y decisiva gestora de derechos de autor. El anticipo, la cantidad de dinero que va a recibir el autor, se deduce por lo regular del 10\% del precio de venta al público del libro multiplicado por la cantidad de ejemplares. Este mecanismo implica que cuanto mayor sea el tiraje, mayor debe ser el pago que se debe realizar al autor, pero la lógica inversa también debe ser considerada. Si un autor, porque su texto promete un importante volumen de ventas y la competencia por hacerse con los correspondientes derechos de publicación ha elevado su atractivo, recibe un adelanto económico de importancia, entonces la editorial se va a ver obligada a desplegar la mayor cantidad de recursos y con la mayor eficacia posible para 
promocionar y vender el libro. En este caso, si el tiraje resultase escaso o la venta ineficiente, el libro en cuestión estaría produciendo pérdidas irrecuperables. De modo que cuanto más costosa resulte la adquisición de derechos para una editorial, más amplio va a tener que ser el público al que se dirigirá la oferta. Este factor también explica la importancia de la variable dinero en el circuito internacional, pues la adquisición de derechos de autores extranjeros aumenta significativamente los costos de producción. Pero los contratos también son decisivos para la suerte de la literatura mundial porque establecen pautas territoriales y de tiempo para la explotación de los derechos por parte de una editorial. No es lo mismo que una editorial se haga con los derechos de publicación para el mundo, para una zona lingüística o para un país. Tampoco es lo mismo que el tiempo establecido sea de tres, cinco o diez años. Estos dos componentes pueden funcionar como condicionamientos negativos si no van acompañados de una efectiva campaña de promoción y distribución. Entre las cláusulas de los contratos suele hallarse una referida a los derechos subsidiarios, es decir, relativos al uso del contenido del libro en otros formatos, como el cine. Allí queda establecida la participación eventual que podrá tener la editorial dada una eventual transferencia de derechos para otros formatos o soportes, lo que también puede incluir derechos de traducción. Los alcances y particularidades del contrato se van a negociar, normalmente, entre el agente, en carácter de representante del autor, y el encargado de derechos de autor y propiedad intelectual dependiente de la editorial.

Una vez que quedan acordadas las condiciones contractuales bajo las cuales se va a hacer efectiva la publicación, comienza el armado del libro con lo cual también se abre el proceso de producción concreta. Aquí es donde hacen su parte diseñadores e ilustradores, siempre bajo supervisión de algún editor responsable. En caso de que corresponda, antes de darle forma al libro, el texto va a pasar por el proceso de traducción. Para la literatura mundial esta etapa es crucial. Desde ya agrega un costo que no todas las editoriales están en condiciones de solventar. Hay situaciones en las que alguna agencia de financiamiento o programa estatal lo asume, por ejemplo, el Instituto Goethe o el Programa Sur para la traducción de literatura argentina. En otros, corre por cuenta exclusiva de la editorial. Los traductores suelen ser freelancers y ofrecer sus servicios a diferentes editoriales sin ningún tipo de exclusividad. No obstante, la competencia cultural que cada uno pueda poseer lo hace más idóneo para la traducción de determinados textos en lugar de otros. Un experto en cultura española, por ejemplo, va a ser el más indicado para traducir literatura de dicho país, pero esa correspondencia va a presentar cierta versatilidad. Lo que merece ser destacado es que una traducción más o menos literal o más o menos adaptativa puede decidir la suerte del texto en el circuito de recepción. Este fenómeno, por ejemplo, es el que observa William Marling en 
relación con la exitosa traducción al inglés de Cien años de soledad por parte de Gregory Rabassa. Por otra parte, un texto con excesivas complejidades formales suele no llegar a esta fase, puesto que el proceso de traducción, en caso de que aún resulte imaginable, sería más costoso y las posibilidades de buena acogida por parte de un público amplio naturalmente menores. Como ha examinado Rebecca Walkowitz en su libro Born Translated: The Contemporary Novel in an Age of World Literature (2015) en la actualidad existen cada vez más textos redactados en vistas de posteriores traducciones. Esto supone la implementación de diferentes técnicas como un estilo desprovisto de culturemas y marcas dialectales, el uso de diferentes lenguas, y narradores pedagógicos que parecieran dirigirse a un público no iniciado. No es de extrañar, por lo tanto, que al considerar riesgos y costos, este estilo, que simplifica la tarea del traductor, resulte favorecido frente a fórmulas más dependientes de su contexto original o con mayor apuesta experimental. En los casos en que el texto ya ha sido aprobado pero que presenta ciertas asperezas para una efectiva recolocación contextual, es decir, que no ha nacido del todo traducido, la traducción va a operar tanto como una transferencia a otro código lingüístico como una adaptación a las condiciones de recepción. Cuando el texto no requiera traducción, aunque sí tal vez una adaptación a condiciones culturales o de mercado diferentes a las que sirvieron de marco para la redacción, el proceso de corrección de estilo va a desempeñar una función clave. Así, por ejemplo, recuerda Evelio Rosero el proceso de corrección al que fue sometido el manuscrito de su texto Juliana los mira cuando se lo preparaba para la publicación en la editorial Anagrama después de haber sido finalista del Premio Herralde de Novela en 1986:

Padecí varios días con sus noches, sin lograr dormir, corrigiendo al corrector, página por página, y eran más de 200 páginas. Allí donde yo ponía matera, ese recipiente por lo general de barro donde los colombianos sembramos las matas, me habían puesto maceta. $\mathrm{Y}$, si bien es cierto que los colombianos entendemos como sinónimos matera y maceta, sin ningún problema, tampoco yo podía aguantar las macetas, o sus macetazos. En cierto modo, fue también mi primera experiencia con las traducciones. Pues, de hecho, siendo como era un escritor en español, me estaban traduciendo al español. Temible descuido: cualquier regionalismo, español o mexicano o argentino enriquece el acervo lingüístico, fortalece y universaliza el idioma. Qué bueno que a través de la literatura sepamos que pibe es chavo o chamo y que chamaco es pelao y que escuincle culicagao y que magrear es abejorrear y hostia es mierda o carajo o golpe y un kikí es un braguetazo y una güera es una mona y otra mona es una rasca y que etcétera es etcétera. Etcétera. En Juliana, donde yo escribía, por ejemplo, debe ser que Juliana está enferma, los correctores corregían: debe de $s e r$, y ese debe de era para mí peor que un martillo en los tímpanos. $(46)^{5}$

5 Para mayores precisiones al respecto, puede consultarse Locane "Más allá...”. 
Para una mejor comprensión, el "padecimiento" de Rosero en realidad debe ser interpretado como una resistencia personal del escritor a la adaptación por la que todo texto debe pasar al momento de ser insertado en tramas de circulación internacional. Si el texto no ha sido redactado desde un comienzo en función de esa circulación internacional, como es el caso, en principio, de la literatura estudiada por Walkowitz, las instancias de corrección y/o traducción van a constituir procedimientos fundamentales para mejorar la transparencia del texto y con ello su accesibilidad para lectores con un respaldo cultural desplazado. Conviene considerar que el caso de Rosero se remonta al año 1986 y que desde entonces la evolución de los mecanismos de producción de literatura ha seguido la de las transformaciones geopolíticas, de modo que esa resistencia responde a parámetro culturales que con la literatura concebida para la traducción se han debilitado.

La función de traductores y correctores resulta, por lo tanto, decisiva en el proceso de producción de literatura mundial. Ninguna estructura productiva que pretenda cierta efectividad en tal nivel puede prescindir de sus servicios. En particular la competencia bicultural de los traductores es de importancia gravitante para el éxito de un texto en el contexto de recepción. Ambos, traductores y correctores, suelen ser freelancers aunque con vínculos regulares con algunas editoriales en concreto, y el pago que reciben, al margen de que encarece de manera ineludible la cadena productiva, debe entenderse como una justa compensación por hacer el texto más accesible a un público con competencias culturales circunscriptas y expectativas específicas. Su acción se complementa con la de los lectores -con quienes es posible que intercambien funciones- en la medida que no es extraño que estos ya hayan señalado en el informe de lectura qué tipo de adaptaciones formales serían necesarias o deseables. El encadenamiento de las acciones de lectura, corrección y/o traducción, siempre seguido de cerca por el editor, permite configurar un texto, empezando por el título y en casos por la rotulación genérica, redactado siempre más o menos en colaboración entre los diversos actores competentes (autor, lector, redactor, corrector y/o traductor, pero en ocasiones también con participación, aunque sea indirecta, del agente y el editor), para el consumo de un público curioso por cierta diferencia cultural, pero no necesariamente especialista en ella.

La etapa de producción del texto se articula con la de producción del soporte. La planificación general elaborada en el momento de preproducción comienza a materializarse: el libro se inserta en la colección prestablecida, se anuncia como novedad en el catálogo, se diseña el lay out con un tipo de fuente determinada, con ilustraciones o no, todo en función del formato en tapa dura, blanda, de bolsillo, etc., se selecciona el tipo de papel, se redacta la nota biográfica, la 


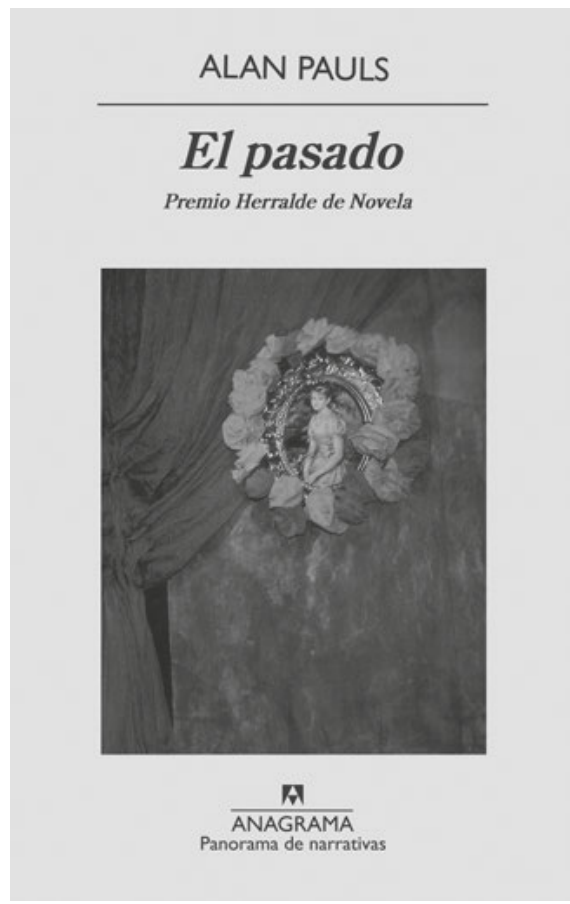

Fig. 1: Portada de El pasado (2003), de Alan Pauls (@ Editorial Anagrama 2003. Diseño de colección: Julio Vivas. Ilustración:

“Hafen Bar”, Nan Goldín, Berlín, 1991).

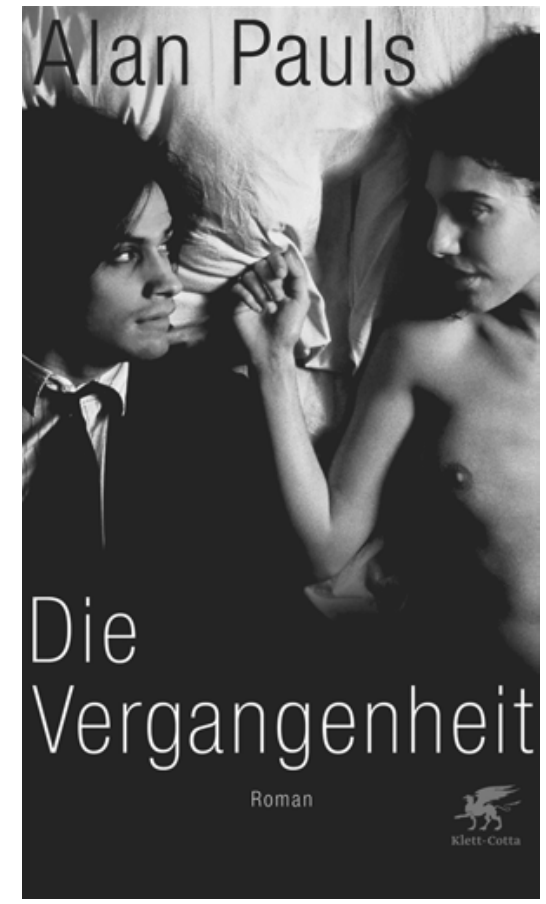

Fig. 2: Versión en alemán de El pasado: Die Vergangenheit (2009) (@ Klett-Cotta 2009. Concepto de portada: Balk \& Brumshagen. Imagen: de la película El pasado, de Héctor Babenco).

contraportada. El diseño de tapa no es un asunto menor en la literatura mundial. Si un texto en el contexto de emergencia puede hablar por sí mismo, o desde el título o desde el nombre del autor, en el de recolocación suele requerir cierta asistencia visual o didactismo para reforzar su atractivo ante el público. Valga el caso de El pasado, de Alan Pauls, como ejemplo. La edición en castellano apareció en Anagrama, en el año 2003, en la colección Narrativas Hispánicas con la habitual tapa en gris de la colección y una caja en el centro con una imagen que reproduce la fotografía "Hafen Bar", de Nan Goldin (Fig. 1). La versión en alemán, traducida por Christian Hansen y publicada por Klett-Cotta en 2009 bajo el título Die Vergangenheit, posee, como portada, un cuadro de la adaptación cinematográfica en la que se ve a Gael García Bernal -ícono del cine 


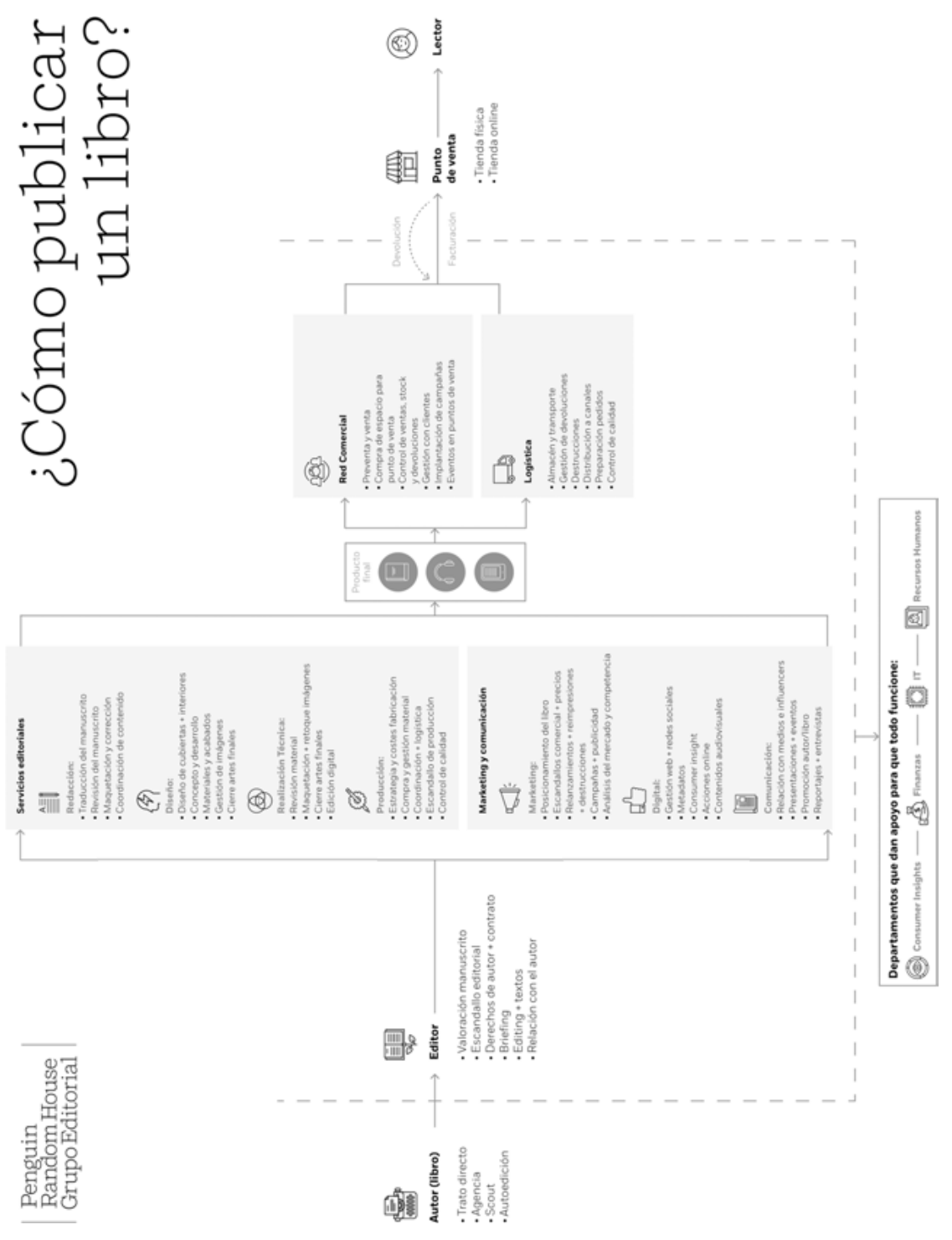

Fig. 3: Cadena productiva del libro según Penguin Random House. [Fuente: sitio Web @ 2017 Penguin Random House Grupo Editorial] 
“latino” desde su rol protagónico en Diarios de motocicleta (2004) - acostado junto a Analía Couceyro, la otra protagonista y compañera de García Bernal Rímini y Sofía en la película-, desnuda (Fig. 2).

La configuración del paratexto, de la nota biográfica, de la contraportada y de la portada, responde, por lo tanto, a razones estratégicas y de marketing que deben ser planificadas racionalmente por los profesionales responsables. También este aspecto es de importancia considerable para la literatura mundial, pues cumple la función de crear un marco interpretativo, y por lo tanto también de apuntalamiento de los significados del texto, para un público que, de lo contrario, se encuentra relativamente desprovisto de recursos que favorezcan su acercamiento al texto y una asimilación positiva.

La figura 3 retrata de modo resumido la cadena productiva según la concibe actualmente el grupo Penguin Random House.

Una vez que el texto se ha convertido en libro, en un objeto concreto multiplicado por las unidades en efecto impresas, comienza el no menos complejo proceso de posproducción. El libro debe ser promocionado, puesto en circulación y vendido, lo cual implica tanto costos como un despliegue de recursos profesionales. Esta instancia debe ser ágil y efectiva porque el depósito de libros también tiene su costo económico y porque la rotación de novedades es el procedimiento regular en la industria a escala más o menos grande, de modo que el tiempo para conseguir un caudal de ventas satisfactorio va a ser reducido. La campaña de promoción, comprendida por la elaboración de material de merchandising, el anuncio en el catálogo, las presentaciones en ferias o eventos más específicos, los eventos culturales complementarios, la publicidad y la redacción de reseñas ya ha comenzado a ser delineada en la etapa de preproducción y ahora toma forma concreta. Los encargados de ventas y marketing ahora se tornan activos, la distribución alcanza las bocas de ventas y con suerte las mesas de novedades, los anuncios así como las reseñas en periódicos y revistas, eventualmente en blogs y televisión, se reproducen, y las presentaciones con el escritor, en el mejor de los casos en diferentes ciudades, son un mecanismo habitual para la visibilización y venta del libro. Cada una de estas instancias y recursos de promoción tiene un costo económico que se traslada a la expectativa de ventas. Una mención particular merece la redacción de reseñas. Normalmente, van a correr por cuenta de periodistas culturales, en casos independientes y en casos vinculados de algún modo o a la editorial o al grupo multimedios que también es responsable de la publicación. Como ha argumentado Marling basándose en el suplemento cultural del New York Times, las reseñas en publicaciones con tradición y 
prestigio, firmadas por periodistas con reconocimiento en el campo de la literatura mundial, van a resultar clave para la promoción $\mathrm{y}$ comercialización del libro, de modo que los reseñistas también deben ser considerados gatekeepers que facilitan $\mathrm{u}$ obturan el acceso de un texto o escritor al corpus de la literatura mundial. Su función, al margen del aval simbólico que de por sí un nombre puede representar, consiste en insertar el texto en cuestión en tradiciones de lectura familiares para los lectores, así, para el caso de la literatura latinoamericana, no va a resultar extraña una mención del realismo mágico o de algún antecedente de prestigio como Roberto Bolaño. En casos, también es posible que la reseña establezca paralelismos del tipo "el Thomas Mann colombiano" o "un William Faulkner brasilero". Ha observado Marling que estas reseñas, a la hora de asignar valor a un texto, suelen responder al paradigma ideológico occidental, de tal modo que la tendencia va a favorecer las configuraciones textuales alineadas bajo premisas características del multiculturalismo del capitalismo liberal.

Este rápido recorrido por la cadena productiva responde a algunas razones concretas que conviene subrayar y tener presentes. En primer lugar, y con las variaciones que se puedan hallar en los casos específicos, esta estructura compromete una serie de actores y costos ausentes o prescindibles en los procesos productivos que tienen lugar a escala más localizada. El tráfico internacional de textos, ya sea mediante traducción o simple adaptación, al elevar significativamente los costos de producción, exige una eficacia técnica, una racionalización y despliegue de recursos, una planificación y un dispositivo de ventas que garanticen un retorno rápido de la inversión inicial. La participación de profesionales altamente calificados y la retribución que perciben es lo que define a esta estructura como fundamentalmente "profesional" en contraste con las más “artesanales” que permite la escala local. Poder disponer de tantos actores y recursos económicos y controlar las naturales complejidades del orden de lo cultural y de lo económico en función de un producto único y acabado constituye un desafío no al alcance de cualquiera. Por supuesto que existen caminos alternativos o atajos para la producción de traducciones o para la puesta en circulación de literaturas extranjeras: las agencias de financiamiento que promueven la literatura de grupos minoritarios, la traducción por iniciativa personal en blogs o la colaboración entre editoriales autogestionadas pueden ser considerados como tal, pero lo cierto es que un impacto real en los hábitos de lectura del público internacional difícilmente resulte efectivo si no es por la unificación de esfuerzos y el compromiso de los actores mencionados y otros como, en casos, profesores e investigadores. Esta “unificación de esfuerzos”, la confluencia de criterios entre escritores, agentes, lectores, correctores, editores, traductores y 
periodistas culturales en función de un mismo objetivo, debe su buen funcionamiento a una estructura corporativa, a un tinglado que coordine y tenga bajo control las diferentes etapas de la producción. De aquí que ante todo la literatura mundial deba ser considerada un producto colectivo y que las grandes corporaciones de la industria cultural cuenten con ventajas para monopolizar los tráficos a gran escala y, finalmente, logren establecer criterios de selección y jerarquización fundados en principios heterónomos, es decir, una lógica hegemónica o las reglas generales del juego. 